POSTER

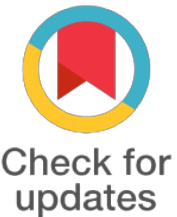

${ }^{*}$ For correspondence:

tcnhat@hcmus.edu.vn

Competing interests: The authors declare that no competing interests exist.

Received: 2017-08-07

Accepted: 2017-08-19

Published: 2017-09-05

Copyright The Author(s) 2017. This article is published with open access by BioMedPress (BMP).

This article is distributed under the terms of the Creative Commons Attribution License (CC-BY 4.0) which permits any use, distribution, and reproduction in any medium, provided the original author(s) and the source are credited.

\section{Assessment of intravenous infused human adipose derived stem cells homing in diabetic mice}

\author{
Nhat Chau Truong, Ngoc Bich Vu, Anh Nguyen-Tu Bui, Cong Le-Thanh Nguyen, \\ Anh Thi-Van Bui, Anh Thi-Van Vu, Loan Thi-Tung Dang, Ngoc Kim Phan \\ Laboratory of Stem Cell Research and Application, University of Science, Vietnam National \\ University HCMC, Ho Chi Minh City, Vietnam
}

\section{Abstract}

Currently, Adipose-derived Stem Cells (hASCs) therapy is being promoted applied research in the treatment of many diseases, especially autoimmune diseases such as systemic lupus erythematosus, rheumatoid arthritis and type 1 diabetes. However, profound mechanisms of this potential therapy have not been understood entirely. It is questioned that which tissues transplanted cells home to, and how long they survive there?

In this work, we evaluated the migration, and survival duration of GFP-expressed hASCs (hASCGFPs) in normal and STZ-induced diabetic mice. A number of $106 \mathrm{hASC}$-GFPs were intravenous transplanted into the mice. After 1, 3, 5, 7 days, the presence of hASC-GFPs in various organs such as heart, lungs, kidneys, spleen, liver and pancreas was detected by Imaging technique (iBox ${ }^{\circledR}$ ExplorerTM Imaging Microscope System_IMS) and the percentage of these cells in the tissues of diabetic mice was evaluated by Flow cytometry (FCM).

The results showed that the transplanted cells could be identified by both IMS and FCM. By IMS, it was clear that hASC-GFPs homed to lung and heart most at day 1 and 3, respectively and the signals were decreased gradually in both tissues. These imaging results were similar in normal and diabetic mice. By FCM, we detected the signals of hASC-GFPs in all six diabetic organs at day 1, 3, 5 , 7. The signals expressed highest at day 1 (liver, heart), day 3 (lungs, kidneys, spleen) or day 5 (pancreas) and all gradually decreased until day 7.

Our results demonstrated that although difficult hASCs could home to the pancreas of normal as well as diabetic mice, but we need more experiments to make further conclusions regards the mechanism of their immigration and behaviour in the recipients

\section{Keywords}

human Adipose-derived Stem Cells, hASCs, Mesenchymal Stem Cell, homing, diabetes

Funding

References 